\title{
MICROWAVE-ASSISTED EXTRACTION OF PHENOLIC ANTIOXIDANTS FROM SEMIARID PLANTS
}

\author{
${ }^{1}$ Jorge E. Wong-Paz, ${ }^{1,2}$ Juan C. Contreras-Esquivel, ${ }^{1}$ Diana Muñiz-Marquez, \\ ${ }^{1}$ Ruth Belmares, ${ }^{1}$ Raul Rodriguez, ${ }^{2}$ Patricia Flores and ${ }^{1}$ Cristobal N. Aguilar \\ ${ }^{1}$ Department of Food Research, DIA-UAdeC, Universidad Autônoma de Coahuila, 25280, Saltillo, Coahuila, México \\ ${ }^{2}$ Coyote Foods Biopolymer and Biotechnology, 25000, Saltillo, Coahuila, Mexico
}

Received 2013-11-18; Revised 2013-12-29; Accepted 2014-03-22

\begin{abstract}
Microwave-Assisted Extraction (MAE) kinetic in three temperatures was investigated for extraction of antioxidant phenolic compounds from Jatropha dioica, Flourensia cernua, Eucalyptus camaldulensis and Turnera diffusa which are plants of semiarid regions of Mexico. The two-site kinetic model and saturation simple equation were used to describe the experimental data. The fit of the data demonstrated that saturation simple equation was better and could explain the data with a slight loss of goodness of fit. The results showed that MAE optimum conditions were extraction temperature of $60^{\circ} \mathrm{C}$ and extraction time in the range from 1 to 6 min. The MAE was more efficient than the conventional Heat Reflux Extraction (HRE). Maximal antioxidant potential was observed in E. camaldulensis extracts. Interestingly differences in phenolic composition and antioxidant activity were observed in the extracts obtained by MAE and HRE for all plants used. Quercetin and catechin were found to be the predominant phenolic compounds. The MAE procedure resulted in suitable alternative to obtain bioactive phenolic compounds from semiarid plants due to this technology is higher efficient than conventional methods increasing yield in shorter times.
\end{abstract}

Keywords: Plant-Extracts, Polyphenols, Antioxidants, Green Chemistry, Modeling Kinetics

\section{INTRODUCTION}

The topic about research on antioxidants has become a topic of increasing interest and it has increased considerably during the past 10 years (Prior et al., 2005) and is tendency continuously increasing up to the present day. Antioxidants naturals are gaining importance due to their benefits for human health where several studies have established an inverse correlation between the intake fruits and vegetables antioxidants and the occurrence of diseases such as inflammation, cardiovascular disease and cancer and to prevent the deterioration of fats and other constituents of foods (Moure et al., 2001; Huang et al., 2005; Routray and Orsat, 2011). In addition to antioxidant activity, several studies demonstrated the antimicrobial activity making them a good alternative to antibiotics and chemical preservatives (Oliveira et al., 2008).
Recently, synthetic antioxidants have shown serious side effects. Therefore, exists an interest towards research on vegetable sources for identifying new antioxidants that could be used in the substitution of natural substances antioxidants instead of the synthetic ones (Chan et al., 2011; Périno et al., 2011; Li et al., 2012).

Vegetable materials contain many compounds with antioxidant activities which are obtained in form of plants extracts. However, polyphenols are the major plant compounds with antioxidant activity and other several activities associated with healthy properties ascribed to their antioxidant activity and free radical scavenging abilities (Kähkönen et al., 2001; Huang et al., 2005; Bakkali et al., 2008).

Extraction represents the primary step in getting crude extract from plants. Plant extract have been obtained commonly by conventional solvent extraction.

Corresponding Author: Cristobal N. Aguilar, Department of Food Research, DIA-UAdeC, Universidad Autônoma de Coahuila, 25280, Saltillo, Coahuila, México 
Conventional extraction techniques include soaking, maceration, water percolation, soxhlet extraction. despite of this, conventional extraction methods have been associated with high solvent requirements of toxic organic solvents, usually required long extraction time which increased risk of degradation of thermo-labile constituents and resulting in low yields of extraction (Ballard et al., 2010; Chan et al., 2011; Wu et al., 2012).

Moreover, with the increasing energy prices, the drive to reduce $\mathrm{CO}_{2}$ emissions and eliminate the hazardous substances used in or generated by a method into the context of green chemistry, food industries are challenged to find or development new technologies in order to reduce energy consumption, product/process safety and control and for cost reduction and increased quality as well as functionality (Keith et al., 2007; Yan et al., 2010; Périno et al., 2011).

Over the past decade, various novel extraction techniques have been introduced and investigated, most of which were claimed to be better in terms of sustainability due to its efficiency and decrease extraction time and solvent consumption.

Interest in Microwave-Assisted Extraction (MAE) has increased significantly over the past 5-10 years in particular medicinal plant research, as a result of its inherent advantages as special heating mechanism, moderate capital cost and its good performance under atmospheric conditions (Ballard et al., 2010; Chan et al., 2011). In addition, MAE technique possesses many advantages compared to other methods for the extraction of compounds such as bioactive compounds (Sanchez-Aldana et al., 2013) saving in processing time and solvent, higher extraction rate, better products with lower cost, reduced energy consumption (up to 85-fold savings) and waste generation (Hao et al., 2002; Yan et al., 2010; Yemis and Mazza, 2012). Therefore, microwave-assisted extraction is an interesting, potential and powerful alternative to conventional liquid solvent extraction methods, especially in the case of plant material (Hao et al., 2002).

Evaluating extractions variables, there are some tools based on experimental studies called mathematical models. Mathematical models provide information that know-how helps the designers and researchers find the best design parameters and the most effective process conditions to optimize purposes and are gaining more attention in food systems. It is important to develop models for the extraction process where different extraction operating parameters are optimized for process economics (Ho et al., 2008). One of them is kinetic model which offers excellent basis for curve fitting as a function of process conditions of both the extraction medium and the extracting plant material is a useful tool for an objective, fast and economic assessment of any processes (Karacabey et al., 2011).

In Mexico have been reported several plant species with several beneficial properties mainly due to have developed ability to grown under extreme climatic conditions. It development a pool of chemical compounds produced as defense mechanism environmental. Actually, extracts of this kind of plants have been used effectively in test as inhibitors pathogenic bacterial and fungal (Castillo et al., 2008; Jasso de Rodriguez et al., 2011) and antioxidants properties have been explored poorly. Besides, there is a lack of knowledge about phytochemicals compounds presents in these plants. Examples of these plants are $J$. dioica (Dragon's blood), F. cernua (Tar bush), T. diffusa (damiana) and E. camaldulensis (Eucalyptus) which are plants of semiarid region of Mexico.

Recently, our research has focused on developing novel processes that will be both economically and substantially acceptable such as MAE in the isolation of the biological active compounds from vegetal materials. To the best of our knowledge, there is no report published on the use of MAE to extract phenolic antioxidants from plants used. Thus, the objectives of the current study were to investigate the effects of MAE on the extraction efficiency and recovery of polyphenolic antioxidant compounds from $J$. dioica, F. cernua, $T$. diffusa and E. camaldulensis plants and fit the experimental datas using empirical models in order to explain and provide useful information for future optimizations. A comparison was also drawn with results obtained using conventional heat reflux extraction.

\section{MATERIALS AND METHODS}

\subsection{Chemicals and Standards}

Pyrogallol (PG), Gallic Acid (GA), Resorcinol (RS), Chlorogenic Acid (CHA), Methyl Gallate (MG), Coumaric Acid (CUA), Catechin (CAT), 2Hydroxycinnamic Acid (HA), Ellagic Acid (EA), Quercetin (QE), Cinnamic Acid (CA), 2,20-diphenyl-1picrylhydrazil (DPPH) free radical, linoleic acid, FolinCiocalteu (FC) reagent were purchased from SigmaAldrich. HPLC-grade Acetonitrile (ACN), acid acetic, methanol and ethanol were purchased from Labscan.

\subsection{Sample Materials}

The plants used in this study were $J$. dioica (stem and root), F. cernua (stem and leaves), T. diffusa (stem and 
leaves) and E. camaldulensis (leaves) collected near Saltillo City, Coahuila, Mexico from January to June 2011. The samples were dried for $48 \mathrm{~h}$ at $60^{\circ} \mathrm{C}$ in an oven (LABNET International, Inc.,) and then they were ground and pass through a $0.6-0.8 \mathrm{~mm}$ screen. The fine and dried powder was stored in sealed hermetically bags and under darkness until use in the MAE.

\subsection{MAE Procedure}

Phenolic compounds were extracted from plants using pressurized MAE system (Ethos Synth, Milestone, Bregamo, Italia). Aqueous ethanol was used as safe and efficient solvent for the extraction of phenolic compounds (Wu et al., 2012) and ethanol is used in the food industry (Li et al., 2012). In the study MAE procedure was carried out as following: $4 \mathrm{~g}$ of material vegetal dried powder was suspended in $120 \mathrm{~mL}$ of ethanol (50\% for $J$. dioica and $35 \%$ for $F$ cernua, $T$. diffusa and $E$. camaldulensis according to previous studies) in a $240 \mathrm{~mL}$ Teflon extraction vessel. The vessel were placed at the center of the microwave apparatus and heated to desired temperature in $1 \mathrm{~min}$ (control time) and after the kinetics was realized at 3,6 and $9 \mathrm{~min}$. Microprocessor EasyWAVE 4 software interface allows direct continuous monitoring and control of parameter evaluated. The temperature in the vessel was directly measured using a thermocouple type thermometer. The mixture was stirred with a magnetic stirrer bar for homogeneous heating. After microwave heating, the mixture in the extraction vessel was allowed to cool down $\left(1 \mathrm{~min}\right.$ at $\left.20-24^{\circ} \mathrm{C}\right)$ using Criolab apparatus and immediately filtered using gauze. After, the extracts were centrifuged at $3000 \mathrm{rpm}$ during $10 \mathrm{~min}$, filtered using filter paper fine pore and dried in an oven at $60^{\circ} \mathrm{C}$ for $24 \mathrm{~h}$. Samples were extracted in triplicate for each plant. Three kinetics extractions were followed for the three irradiation temperature used $\left(50,60\right.$ and $\left.70^{\circ} \mathrm{C}\right)$.

\subsection{Heat-Reflux Extraction (HRE)}

With the purpose of compare the extraction efficiency of MAE, heat-reflux extraction was performed and considered as conventional method. Previous studies show the suitable extraction conditions of these materials under reflux-heat. Hence, in the present study, $20 \mathrm{~mL}$ ethanol-aqueous $(35 \%, \mathrm{v} / \mathrm{v})$ was added to $5 \mathrm{~g}$ dried powder of the materials vegetal ( $F$ cernua, $T$. diffusa and E. camaldulensis) and extracted under refluxing at $60^{\circ} \mathrm{C}$ for $2 \mathrm{~h}$ of extraction. For J. dioica, a solid-to-solvent ratio of $1: 15(\mathrm{~g} / \mathrm{mL})$ and ethanol-aqueous $(70 \%, \mathrm{v} / \mathrm{v})$ were used. The extracts were centrifuged, filtered and dried in an oven at $60^{\circ} \mathrm{C}$ for $24 \mathrm{~h}$. The extracts were stored in eppendorf tubes in refrigeration until use. The extractions were realized in triplicate. For all the determinations, the extracts were re-suspended in water (1 mg of dried extract $/ \mathrm{mL})$.

\subsection{Total Phenolic Content (TPC)}

TPC in the obtained extracts were estimated by colorimetric assay according at methodology reported by Makkar (1999) with some modifications. First, $800 \mu \mathrm{L}$ of sample was mixed with $800 \mu \mathrm{L}$ of Folin and Ciocalteu's reagent. After $5 \mathrm{~min}, 800 \mu \mathrm{L}$ of $\mathrm{Na}_{2} \mathrm{CO}_{3}(0.01 \mathrm{M})$ was added and kept for $5 \mathrm{~min}$. Finally the solution was diluted with $5 \mathrm{~mL}$ of distilled water and the absorbance was read at $790 \mathrm{~nm}$ (Varian 50 Bio Spectrophotometer). Gallic acid was used for constructing the standard curve (0-300 $\left.\mathrm{mgL}^{-1}\right)$. The results are expressed as $\mathrm{mg}$ gallic acid equivalents/g of material vegetal.

\subsection{Antioxidant Activity}

Antioxidant activity was measured only for the extracts that presented high amount of polyphenolic compounds in each vegetal material by MAE and for all extracts obtained by conventional extractions. Antioxidant activity was measured for two methods, DPPH free radical-scavenging activity and inhibition of the oxidation of linoleic acid.

\subsubsection{DPPH (1,1-Diphenyl-2-Picryl-Hydrazil) Radical Scavenging Activity}

The antioxidant capacity of the obtained extracts was evaluated as the DPPH free radical-scavenging activity according to a method reported by (Bondet et al., 1997; Molyneux, 2004) with some modifications: $193 \mu \mathrm{L}$ of the methanolic solution of free radical DPPH $(60 \mu \mathrm{M})$ was added to $7 \mu \mathrm{L}$ of the sample extract and let stand for $30 \mathrm{~min}$ at room temperature before the absorbance was measured at $517 \mathrm{~nm}$ using a spectrophotometer microplate reader (Epoch, BioTek, Instruments, Inc.,) controlled with the Gen5 Data Analysis software interface. The free radical-scavenging activity of the extracts was expressed as the percentage of DPPH reduced and was calculated according to the equation:

$$
\text { Inhibition of } \operatorname{DPPH}(\%)=\frac{\left(\mathrm{A}_{\mathrm{c}}-\mathrm{A}_{\mathrm{s}}\right)}{\mathrm{A}_{\mathrm{c}}} * 100
$$

where, Ac is the absorbance of the control $(7 \mu \mathrm{L}$ of water instead of sample) and As is the absorbance of the sample.

\subsubsection{Lipid Oxidation Inhibition Assay}

The antioxidant activity was estimated according to Martínez et al. (2011). The method is based on the 
spectrophotometric assay of primary products of linoleic acid peroxidacion (dienes) which may be inhibited or stimulated by compounds presents in the extracts (Starzynska et al., 2008). Firsts, the linoleic acid solution was prepared by diluting $0.56 \mathrm{~g}$ of linoleic acid and $1.5 \mathrm{~g}$ of Tween 20 in $8 \mathrm{~mL}$ of $96 \%$ ethanol. Each plant extract $(50 \mu \mathrm{L})$ was mixed with linoleic acid solution $(100 \mu \mathrm{L})$ and $1.5 \mathrm{~mL}$ of $0.02 \mathrm{M}$ acetate buffer ( $\mathrm{pH} 4.0$ ). Controls contained $50 \mu \mathrm{L}$ of distilled water. The samples were homogenized in vortex and incubated at $37^{\circ} \mathrm{C}$ for $1 \mathrm{~min}$. After $1 \mathrm{~min}, 750 \mu \mathrm{L}$ of $50 \mathrm{M} \mathrm{FeCl}_{2}$ solution $(0.0994 \mathrm{~g}$ $\mathrm{FeCl}_{2}$ and $0.168 \mathrm{~g}$ EDTA diluted to $1 \mathrm{~L}$ with distilled water) were added to induce oxidation of linoleic acid. Two aliquots $(250 \mu \mathrm{L})$ were taken, at 1 and $24 \mathrm{~h}$. Each aliquot was processing in the moment as following: Aliquot were added to $1 \mathrm{~mL}$ of $0.1 \mathrm{M} \mathrm{NaOH}$ in $10 \%$ ethanol to stop the oxidation process and diluted with $2.5 \mathrm{~mL}$ of $10 \%$ ethanol. The absorbance was measured at $232 \mathrm{~nm}$ against $10 \%$ ethanol blank. Percent inhibition of linoleic acid oxidation was calculated with the following equation:

$$
\text { Lipid oxidation inhibition }(\%)=\frac{(\mathrm{A}-\mathrm{B})}{\mathrm{A}} * 100
$$

where, $\mathrm{A}$ is the difference between the absorbance of the control sample (distilled water) after $24 \mathrm{~h}$ and $1 \mathrm{~h}$ of incubation and $\mathrm{B}$ is the difference between the absorbance of each extract sample after $24 \mathrm{~h}$ and $1 \mathrm{~h}$ of incubation.

\subsection{HPLC Analysis}

The extracts obtained under same conditions of the extracts used in the antioxidant activity were injected in the HPLC system for the characterization of the phenolic compounds presents. Qualitative analysis was carried out in a Varian Pro-Star 330 system equipped with a DAD detector (Varian Inc., USA). The monitoring wavelength was $280 \mathrm{~nm}$. Fractionation of the samples was performed on an Pursuit XRs C18 column $(5 \mu \mathrm{m}, 150 \times 4.6 \mathrm{~mm}$, Varian Inc.) at $30^{\circ} \mathrm{C}$ with flow rate of $1 \mathrm{~mL} / \mathrm{min}$. Acetic acid $(3 \%)$ and acetonitrile were used as mobile phase, A and $\mathrm{B}$ respectively. The injection volume was $10 \mu \mathrm{L}$ (sample previously filtered through a $0.22 \mu \mathrm{m}$ nylon membrane). Gradient used was: Initial, $0 \% \mathrm{~B} ; 0-1 \mathrm{~min}$, $3 \% \mathrm{~B} ; 1-3 \mathrm{~min}, 10 \% \mathrm{~B} ; 3-8 \mathrm{~min}, 20 \% \mathrm{~B} ; 8-13 \mathrm{~min}, 30 \%$ B; $13-18$ min, $50 \%$ B. The column was then washed and reconditioned. All the solutions standard of the different polyphenolic compounds used were injected in the same manner (Ruiz-Martínez et al., 2011).

\subsection{Data Analysis}

Nonlinear regression analysis and the fit MAE experimental data were performed using Microsoft Excel software. MAE experimental data were fitted by minimization of the sum of squares error to the proposed models. The goodness of fits was assessed using determination coefficient $\left(\mathrm{R}^{2}\right)$.

\subsubsection{Mathematical Models}

MAE overall experimental data were fitted with three empirical mathematical models: Two-site kinetic model (Karacabey et al., 2011) and saturation simple equation in order to determine the best model describing the behavior of microwave-assisted extraction of TPC in semiarid region plants studied.

In two-site kinetic model the equation followed was:

$$
\mathrm{Ct}=\mathrm{C}_{\mathrm{eq}}\left[1-\left[\mathrm{F} \cdot \mathrm{e}^{\left(-\mathrm{k}_{1} \cdot \mathrm{t}\right)}\right]-\left[(1-\mathrm{F}) \cdot \mathrm{e}^{(-\mathrm{k} 2 . \mathrm{t})}\right]\right]
$$

Where:

$\mathrm{C}_{\mathrm{t}} \quad=$ The solute a concentration in liquid phase any time $\mathrm{t}$ ( $\mathrm{mg}$ solute $\mathrm{A} / \mathrm{g}$ vegetal material)

$\mathrm{C}_{\mathrm{eq}}=$ The equilibrium solute a concentration (mg solute $\mathrm{A} / \mathrm{g}$ vegetal material)

$\mathrm{F} \quad=$ The fraction of the solute released quickly

$(1-\mathrm{F})=$ The fraction of the solute released slowly

$\mathrm{k}_{1} \quad=$ The first-order rate constant describing the fast released fraction $\left(\mathrm{min}^{-1}\right)$ and

$\mathrm{k}_{2}=$ The first-order rate constant describing the slow released fraction $\left(\mathrm{min}^{-1}\right)$

Saturation simple equation was considered to describe the extraction kinetics of a target compound into a liquid solution. Then, the equation was used as:

$$
\mathrm{C}_{\mathrm{t}}=\left(\mathrm{C}_{\mathrm{eq}} * \mathrm{t}\right) /(\mathrm{k}+\mathrm{t})
$$

Where:

$\mathrm{C}_{\mathrm{t}}=$ The solute a concentration in liquid phase any time $\mathrm{t}$ (mg solute $\mathrm{A} / \mathrm{g}$ vegetal material)

$\mathrm{C}_{\mathrm{eq}}=$ The equilibrium solute a concentration (mg solute $\mathrm{A} / \mathrm{g}$ vegetal material)

$\mathrm{k}=$ The constant that describing the released fraction $\left(\min ^{-1}\right)$

\section{RESULTS}

\subsection{MAE Procedure Behavior}

In the present study, different temperatures were tested for the TPC extraction from several semiarid region plants of Mexico using MAE procedure. Two empirical models (two-site kinetic model and saturation simple equation) were assessed to describe the extraction 
progress of target compounds during the kinetics performed. R2 values of each model were considered for the assessment of model adequacies (Table 1 and 2). The results implied that both models used could describe the extraction of total phenolic compounds present in the plants used with the change of temperature in the studied ranges. However, checking model adequacies, J. dioica kinetics displayed lower goodness of fit in the two kinetics used with respect to the other plants kinetics. Generally, saturation simple equation was concluded to be the best model describing the extraction of TPC using MAE procedure in the plants used showing high performance to explain the experimental data obtained. Depending on the purpose, both equations could be used to achieve good estimation of extraction system of TPC under the studied range of temperature at least for $\mathrm{F}$. cernua, T. diffusa and E. camaldulensis. Experimental date and theoretical curves fitted of MAE procedure are presented in the Fig. 1 and 2.

\subsection{Model Fitting for MAE Procedure}

Two-site kinetic model is knowledge for present goodness of fit curve extractions, it could be attributed to the model has two term groups separately describing the fast and the slow parts of extraction. Figure 1A-D shows the fitted curves for extraction yields of TPC at three different temperatures using the two-site kinetic model. The effect of temperature on the extraction of TPC indicated the maximum recoveries was reached at around $60-70^{\circ} \mathrm{C}$ for the four plants studied. The plots show that the values calculated from the model adequately match the experimental values $\left(\mathrm{R}^{2}>0.98\right)$. Models parameters used to fit the experimental data with this model are presented in Table 1. The equilibrium concentrations calculated for TPC increased with increasing temperature, however no significant difference are presented between 60 and $70^{\circ} \mathrm{C}$ in J. dioica, F. cernua and $T$. diffusa extracts. In the other hand, asymptotic values were observed for $E$. camaldulensis extract with change of temperature. The equilibrium concentration of E. camaldulensis was found to be increased from 50 to $60^{\circ} \mathrm{C}$ temperatures and slightly decreased with further increase up to $70^{\circ} \mathrm{C}$ (Table 1). The $\mathrm{F}$ values no displayed change for $J$. dioica. In contrast, the values $\mathrm{F}$ for $\mathrm{F}$. cernua show a slight tendency of increase with increase in extraction temperature and besides these values were very close to 1 , which indicated that the higher portion of target solute was removed from material vegetal during the fast rate of process. For the $T$. diffusa and $E$. camaldulensis extracts the influence of increase in extraction temperature on the $\mathrm{F}$ values were in asymptotic values, implying that for $T$. diffusa using $60^{\circ} \mathrm{C}$ temperature allowed the fraction of extractable solute content removed was faster than the other temperatures, in contrast where $60^{\circ} \mathrm{C}$ was used in E. camaldulensis the fraction of extractable solute decreased.

The effects of extraction temperature on the fast and slow extraction rates constants $\left(\mathrm{k}_{1}\right.$ and $\mathrm{k}_{2}$, respectively) were already investigated. The fast extraction rate constant $\left(\mathrm{k}_{1}\right)$ in $J$. dioica indicated a slight decrease when $70^{\circ} \mathrm{C}$ were used. In contrast, for F. cernua increase in the temperature caused increase in the fast extraction rate constant implying that the extraction at elevated temperatures $\left(60-70^{\circ} \mathrm{C}\right)$ provides the fastest extraction of the quickly release solutes in the very early part of the extraction. Similar behavior was observed in the fast extraction rate constant for $T$. diffusa and $E$. camaldulensis where increase in the temperature from 50 to $60^{\circ} \mathrm{C}$ caused slightly decreased in the $\mathrm{k} 1$ and then increase with increasing temperature in from 60 to $70^{\circ} \mathrm{C}$ indicated that $60^{\circ} \mathrm{C}$ is a point where extraction velocity of the faster fraction of extractable solute was slightly slower than 50 and $70^{\circ} \mathrm{C}$.

Slow extraction rate constants $\left(\mathrm{k}_{2}\right)$ for $J$. dioica, $F$. cernua and $T$. diffusa no significant change were observed with increased in the temperature. Nevertheless, in $E$. camaldulensis shifting the extraction temperature from 50 to $60^{\circ} \mathrm{C}$ caused an increase in the slow rate constant and negligible shifting was observed from 60 to $70^{\circ} \mathrm{C}$.

Saturation simple equation described best the experimental data for MAE procedure in the TPC extraction for the present study. Model parameters, equilibrium concentration $\left(\mathrm{C}_{\mathrm{eq}}\right)$ and extraction rate constant $(\mathrm{k})$ were determined by fitting the experimental data and are presented in Table 2. High goodness of fit for Model equation indicated that extraction of TPC from plants studied could be adequately described by this model. The experimental and theoretical extraction curves are shown in the Fig. 2A-D. The advantage of Monod's equation against Two-site kinetic model is that first one is composed only for two terms whereas second one include four terms making the model more complicated (Karacabey et al., 2011).

In the same way as two-site kinetic model, the equilibrium concentrations $\left(\mathrm{C}_{\mathrm{eq}}\right)$ of TPC indicated the increase in those values with increasing temperature from 60 to $70^{\circ} \mathrm{C}$ in $J$. dioica, F. cernua and $T$. diffusa extracts and asymptotic values were observed for $E$. camaldulensis extract where it was found to be higher value at $60^{\circ} \mathrm{C}$ temperature (Table 2). According to the extraction rate constants, extraction of TPC was accelerated with the increase in temperature from 50 to $70^{\circ} \mathrm{C}$ when J. dioica were used. 
Jorge E. Wong-Paz et al. / American Journal of Agricultural and Biological Sciences 9 (3): 299-310, 2014
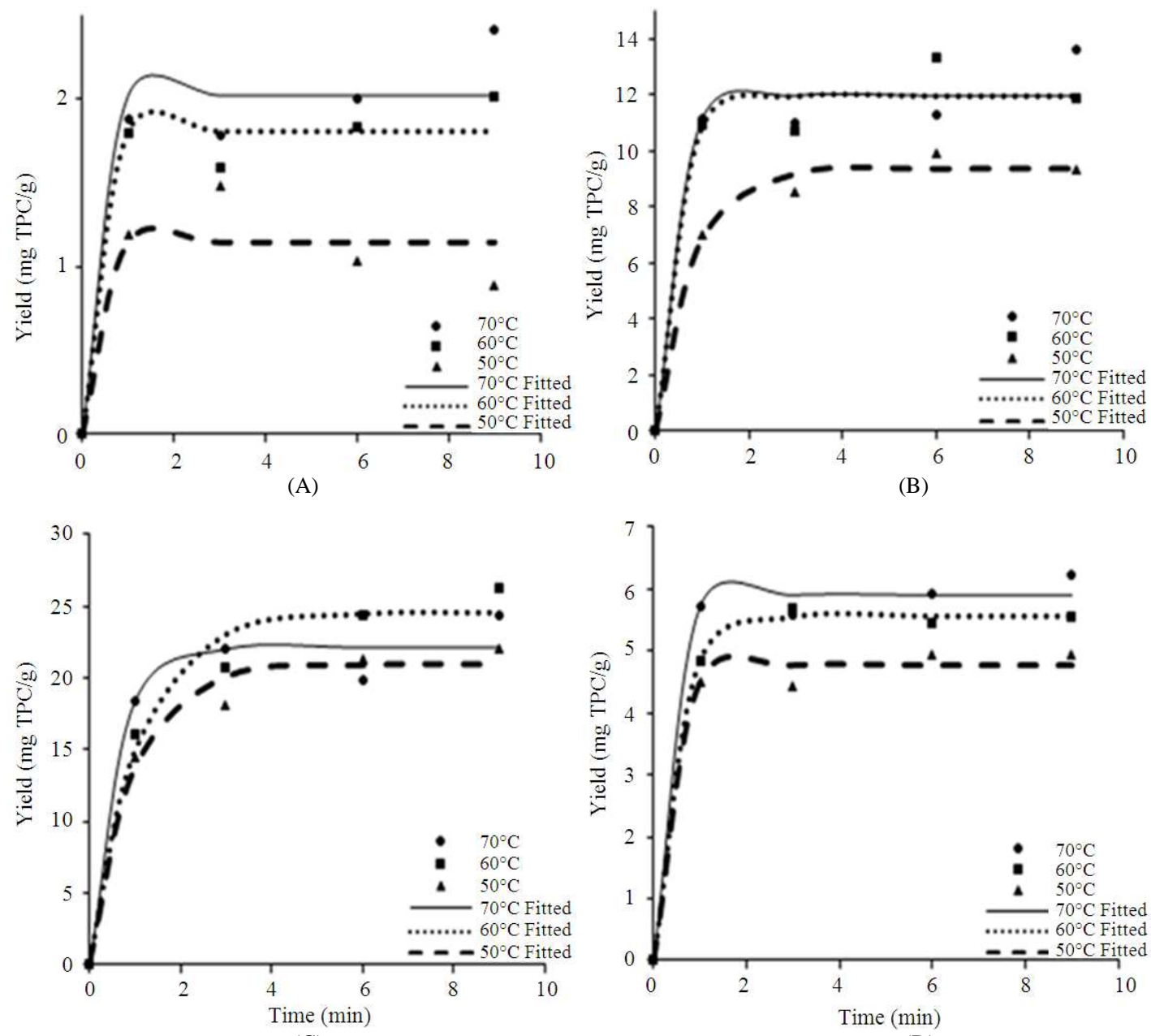

(C)

(D)

Fig. 1. Experimental fitting of two-site kinetic model to TPC recovery data obtained at various temperatures in $J$. dioica (A), F. cernua (B), E. camaldulensis (C) and T. diffusa (D)

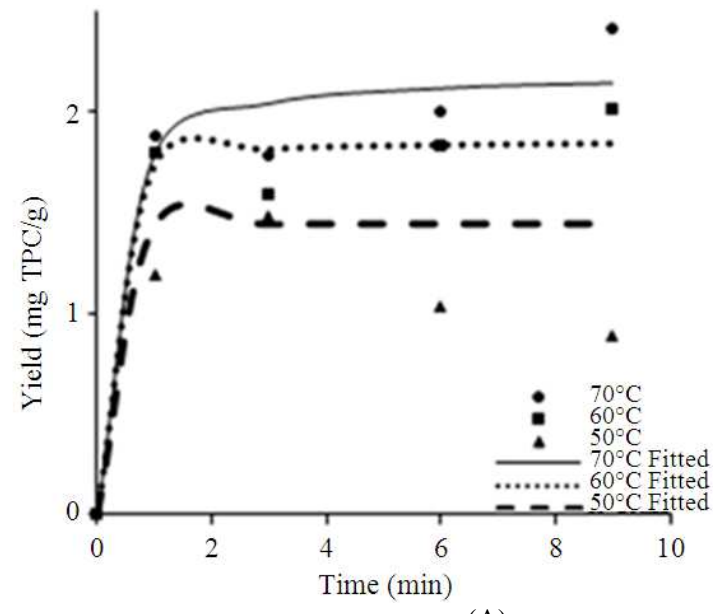

(A)

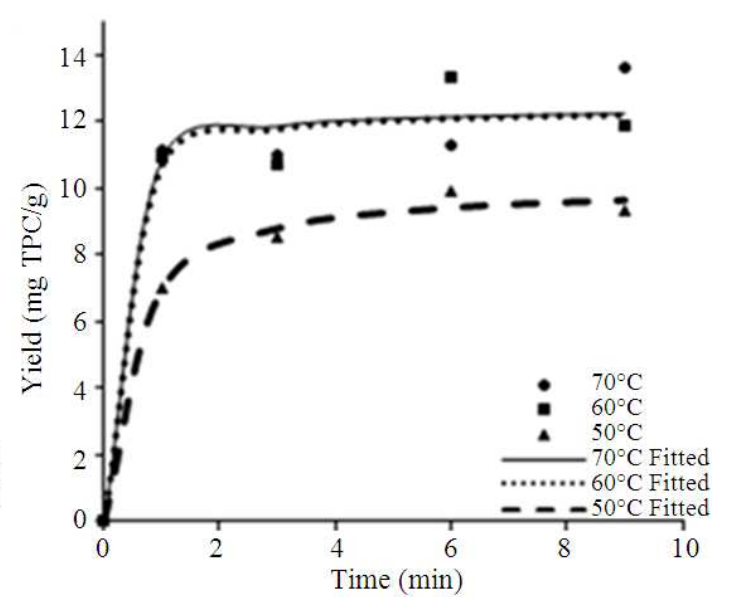

(B) 


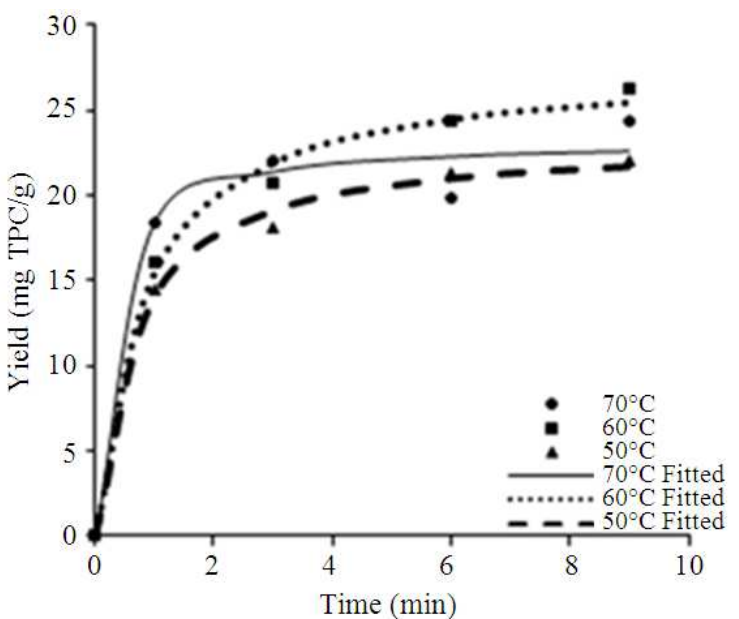

(C)

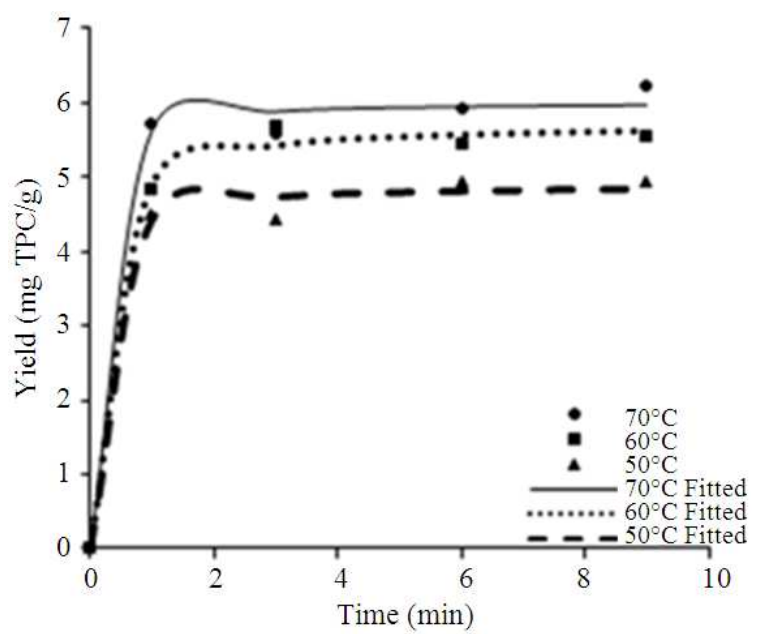

(D)

Fig. 2. Experimental fitting of saturation simple equation to TPC recovery data obtained at various temperatures in $J$. dioica (A), F. cernua (B), E. camaldulensis (C) and T. diffusa (D)

Table 1. Predicted equilibrium concentrations and kinetic parameters obtained in the two-site kinetic model

\begin{tabular}{|c|c|c|c|c|c|c|}
\hline \multirow[b]{2}{*}{ Vegetal material } & \multicolumn{6}{|l|}{ Two-site kinetic model } \\
\hline & Temperature $\left({ }^{\circ} \mathrm{C}\right) \mathrm{MAE}$ & $\mathrm{C}_{\mathrm{eq}}(\mathrm{mg} / \mathrm{g})$ & $\mathrm{F}$ & $\mathrm{k}_{1}\left(\min ^{-1}\right)$ & $\mathrm{k}_{2}\left(\min ^{-1}\right)$ & $\mathrm{R}^{2}$ \\
\hline \multirow{3}{*}{ J. dioica } & 50 & 1.1475 & 1.0000 & 14.8042 & 19.6244 & 0.9195 \\
\hline & 60 & 1.8100 & 1.0000 & 14.8042 & 19.6244 & 0.9827 \\
\hline & 70 & 2.0249 & 1.0000 & 14.6585 & 19.6244 & 0.9663 \\
\hline \multirow{3}{*}{ F. cernua } & 50 & 9.3810 & 0.9969 & 1.3176 & 3.2959 & 0.9944 \\
\hline & 60 & 11.9661 & 0.9998 & 2.3980 & 3.2993 & 0.9848 \\
\hline & 70 & 11.9924 & 0.9999 & 2.6630 & 3.2993 & 0.9824 \\
\hline \multirow{3}{*}{ E. camaldulensis } & 50 & 20.9424 & 0.9918 & 1.0629 & 3.2948 & 0.9912 \\
\hline & 60 & 24.5491 & 0.9871 & 0.9261 & 7.2589 & 0.9889 \\
\hline & 70 & 22.1160 & 1.0000 & 1.7740 & 7.2592 & 0.9859 \\
\hline \multirow{3}{*}{ T. difussa } & 50 & 4.7680 & 0.9999 & 2.8665 & 1.8304 & 0.9952 \\
\hline & 60 & 5.5587 & 1.0000 & 2.0413 & 1.8285 & 0.9993 \\
\hline & 70 & 5.9004 & 0.9999 & 3.4282 & 1.8304 & 0.9962 \\
\hline
\end{tabular}

Table 2. Predicted equilibrium concentrations and kinetic parameters obtained in the saturation simple equation

\begin{tabular}{|c|c|c|c|c|}
\hline \multirow[b]{2}{*}{ Vegetal material } & \multicolumn{4}{|l|}{ Saturation simple equation } \\
\hline & Temperature $\left({ }^{\circ} \mathrm{C}\right) \mathrm{MAE}$ & $C_{e q}(\mathrm{mg} / \mathrm{g})$ & $k\left(\min ^{-1}\right)$ & $\mathrm{R}^{2}$ \\
\hline \multirow{3}{*}{ J. dioica } & 50 & 1.4500 & 0.0100 & 0.9184 \\
\hline & 60 & 1.8608 & 0.0712 & 0.9840 \\
\hline & 70 & 2.2020 & 0.2321 & 0.9770 \\
\hline & 50 & 10.1437 & 0.4555 & 0.9969 \\
\hline \multirow[t]{3}{*}{ F. cеrnua } & 60 & 12.4325 & 0.1648 & 0.9874 \\
\hline & 70 & 12.4499 & 0.1469 & 0.9852 \\
\hline & 50 & 23.2701 & 0.6543 & 0.9979 \\
\hline \multirow[t]{3}{*}{ E. camaldulensis } & 60 & 27.6869 & 0.7944 & 0.9972 \\
\hline & 70 & 23.2560 & 0.2655 & 0.9868 \\
\hline & 50 & 4.8942 & 0.1059 & 0.9966 \\
\hline \multirow[t]{2}{*}{ T. difussa } & 60 & 5.7213 & 0.1677 & 0.9980 \\
\hline & 70 & 6.0116 & 0.0689 & 0.9970 \\
\hline
\end{tabular}


Contradictorily, for $F$. cernua adverse influence of increase in the temperature on $\mathrm{k}$ values was observed implying a slight decrease on the velocity of extraction. Extraction rate constant in the $T$. diffusa and E. camaldulensis newly were observed to have asymptotic values. When 50 and $70^{\circ} \mathrm{C}$ were used in the extraction of the TPC the $\mathrm{k}$ values were lower with respect to $60^{\circ} \mathrm{C}$. Accordingly, $60^{\circ} \mathrm{C}$ accelerated the extraction of TPC in both plants.

\subsection{Effect of Temperature and Time in MAE}

Generally, for all plants used was observed an increase in the yield of TPC $(\mathrm{mg} / \mathrm{g})$ with increase temperature from 50 to $60^{\circ} \mathrm{C}$ and no significant change was observed from 60 to $70^{\circ} \mathrm{C}$. Several studies in MAE had shown that increase in the temperatures could result in the increase of the yield of the target molecules as phenolic compounds (Yan et al., 2010; Li et al., 2012). It could be explained by a phenomenon that has been observed in plant cells after exposure to microwave heating. Which microwave energy is absorbed by solvent causing vibrational effects involves disruption of hydrogen bonds, rotation of molecules and migration of ions that heats the solvent and the free water molecules directly present. The moisture begins to evaporate generates pressure within the cell wall that eventually results in opening of the cell matrix or cell rupture and facility the release of active constituents and allowing the dissolution into the solvent and, therefore improving extraction yield (Ballard et al., 2010; Martins et al., 2010; Chan et al., 2011). Although is knowledge that an increase in the temperature causes a decrease in solvent viscosity and an increase in diffusion, increasing the extraction efficiency. Moreover, increase in temperature causes an increase in the diffusivity, which accelerated the rate of mass transfer and therefore reduced extraction time (Ho et al., 2008) as was described before. However, the effect of temperature on the quality of the phytochemicals of interest depends strongly of the kind of target compounds ( $\mathrm{Li}$ et al., 2012). For polyphenols, the problem with the use of very high temperatures is that may allow side reactions as thermal degradation of the phenols (Ho et al., 2008; Ballard et al., 2010; Yan et al., 2010; Wu et al., 2012). It could explain the fact that $\mathrm{C}_{\mathrm{eq}}$ values increase from 50 to $60^{\circ} \mathrm{C}$ and after decreased from 60 to $70^{\circ} \mathrm{C}$. Hence, according to the previously discussed, $60^{\circ} \mathrm{C}$ was selected as the optimum temperature for extraction in all plants.

The effect of the extraction time is a point very important in the obtaining of extracts and is necessary to select a proper extraction time to assure the complete extraction of the target compounds. Results in Fig. 1 and 2 shows that the solvent saturation using $60^{\circ} \mathrm{C}$ was achieved around of 1 and $3 \mathrm{~min}$ for J. dioica, F. cernua and T. diffusa, however as no significant deference was observed between 1 and $3 \mathrm{~min}, 1 \mathrm{~min}$ was selected for the next experiment for these plants. Similarly, for E. camaldulensis the solvent saturation using $60^{\circ} \mathrm{C}$ was achieved around of 6 and 9 min (Fig. 1c and 2c), hence the extract obtained at 6 min was selected for the next experiment for this plant.

\subsection{Comparison Between HRE and MAE}

Conventional extraction was performed in order to evaluate the extraction efficiency of the yield, phenolic composition and effect in the activity of the extracts using MAE. As shown in Table 3, there are no differences in the extraction yield when $J$. dioica and $\mathrm{F}$. cernua were used in HRE and MAE, however taking into consideration the time needed for extraction, MAE was found to be the best feasible approach for the rapid and efficient extraction of bioactive phenolic constituents. In contrast, there are a significant difference between HRE and MAE for E. camaldulensis and T. diffusa, where MAE improve the extraction efficiency in a $50 \% \mathrm{E}$. camaldulensis and $31 \%$ T. diffusa extracts and reduced the extraction time at 1 and $6 \mathrm{~min}$, respectively. This improve in the extraction efficiency in both plants $E$. camaldulensis and $T$. diffusa could be due to these plants have structure less rigid and contained more free water possibly increasing the degree of cell rupture. Similar results were observed when phenolic compounds were extracted of tomato cultivar using MAE extraction (Li et al., 2012). These authors observed that increasing the temperature allowed increase in the yield and reduced in the extraction time.

The effect of the MAE procedure and HRE on the TPC yield is shown in the Table 3. In the same way, a significant increase $(72 \%)$ in TPC was obtained for the MAE as compared to that of the same sample extracted using the HRE method. On the other hand, for J. dioica, $F$. cernua and $T$. diffusa was observed that TPC was obtained in the same levels between MAE and HRE. Nevertheless, interestingly the HPLC profiles of MAE and HRE extracts were not similar at least for $J$. dioica and F. cernua (Table 4), which suggests that MAE caused modifications in the polyphenolic extracts composition but no in the TPC. In J. dioica using MAE procedure allowed the extraction of the quercetin compound which it was detected in the HPLC analysis for MAE and not in HRE extracts. In contrast, when F. cernua was used in MAE procedure two from three compounds obtained in HRE were not detected in HPLC analysis, chlorogenic and coumaric acids. These compounds are slightly similar in its structure, which 
indicated that MAE irradiation affected directly at these compounds and could originate its degradation. Notwithstanding, MAE procedure allowed to the extraction of four important different phenolic compounds in F. cernua extracts using MAE procedure as namely pyrogallol, resorcinol, methyl gallate and catechin. Only, quercetin compound was present in the both method extraction MAE and HRE in F. cernua. In $E$. camaldulensis and $T$. diffusa similar profiles were observed under the MAE conditions as compared to the conventional extraction method indicated that no phenolic compounds were degraded (Table 4). Actually, there are no reports for the extraction of TPC in these plants using MAE. However, our results are in accordance with findings by other researchers for the extraction of phenolic compounds from different plant materials by MAE, where a few minutes are need to extract the total phenolic content using MAE (Yan et al., 2010; Aspé and Fernández, 2011; Li et al., 2012).

\subsection{Antioxidant Capacity}

Figure 3 shows the potential antioxidant (DPPH and lipid oxidation inhibition) of the extract obtained by MAE and HRE procedure for all plants used. At the concentration used $\left.(1 \mathrm{mg} \mathrm{mL})^{-1}\right)$ the extracts of $\mathrm{F}$. cernua, T. diffusa and E. camaldulensis shows the higher antioxidant capacity in DPPH radical scavenging around of $80 \%$, in both extraction methods, MAE and HRE (Fig. 3A). Lower DPPH radical scavenging was obtained in $J$. dioica extracts, with $26 \%$ approximately.

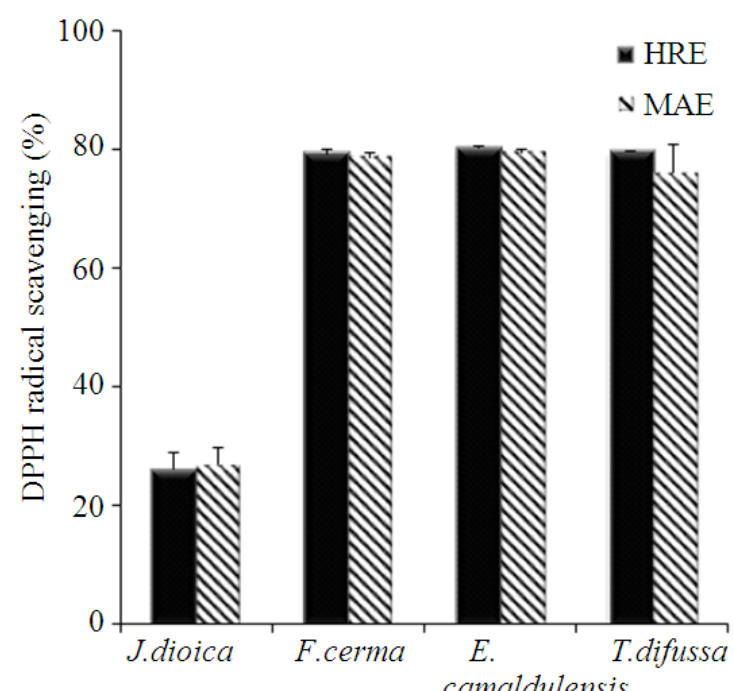

(A)
In contrast, interestingly differences between MAE and HRE were observed in antioxidant activity when lipid oxidation inhibition was tested (Fig. 3B). The extracts obtained by MAE procedure in $J$. dioica were higher than extracts obtained by HRE with an increase of 50\% in the inhibition of lipid oxidation, approximately. While in F. cernua extracts the activity was higher using HRE procedure than MAE in an $30 \%$. The HPLC analysis (Table 4), could explain these results, as discussed before, using MAE affected positively the composition in $J$. dioica, while in F. cernua some polyphenolic compounds were degraded causing decreased in the activity antioxidant. Despite that in F. cernua appears other compounds, it could be in low concentration and the compounds degraded could be the mainly responsible in the contribution of lipid oxidation inhibition. Similarly, in the antioxidant activity of E. camaldulensis extracts obtained by MAE procedure was observed higher lipid oxidation inhibition than HRE extracts (Fig. 3B). According to the results obtained in TPC yield (Table 3) and HPLC assays (Table 4), the yield was increased in MAE and only one predominant phenolic compound was observed in the both extracts (MAE and HRE) suggesting that the increase in its activity observed in MAE could be relation whit an increase in the presence and concentration of this compound. Zuorro and Lavecchia (2013) reported that phenolic compounds extraction was correlated to antioxidant acitivty from other plant material, however generally in our case no correlations were observed.

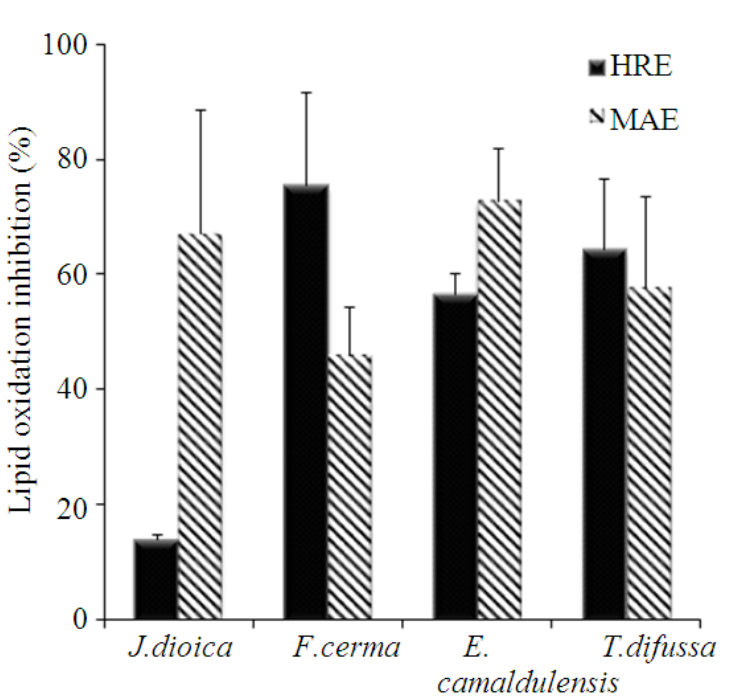

(B)

Fig. 3. Percentages of antioxidant activity in DPPH free radical scavenging (A) and lipid oxidation inhibition (B) tests of the extracts obtained in MAE and HRE 
Jorge E. Wong-Paz et al. / American Journal of Agricultural and Biological Sciences 9 (3): 299-310, 2014

Table 3. Comparison between extraction and TPC yields obtained in MAE and HRE extracts under each conditions selected

\begin{tabular}{|c|c|c|c|c|c|c|c|c|}
\hline \multirow[b]{2}{*}{ Method } & \multicolumn{2}{|l|}{ J. dioica } & \multicolumn{2}{|l|}{ F. cernua } & \multicolumn{2}{|c|}{ E. camaldulensis } & \multicolumn{2}{|l|}{ T. diffusa } \\
\hline & $\begin{array}{l}\text { Extraction } \\
\text { yield }(\%)\end{array}$ & $\begin{array}{l}\text { TPC yield } \\
(\mathrm{mg} / \mathrm{g})\end{array}$ & $\begin{array}{l}\text { Extraction } \\
\text { yield }(\%)\end{array}$ & $\begin{array}{l}\text { TPC yield } \\
(\mathrm{mg} / \mathrm{g})\end{array}$ & $\begin{array}{l}\text { Extraction } \\
\text { yield }(\%)\end{array}$ & $\begin{array}{l}\text { TPC yield } \\
(\mathrm{mg} / \mathrm{g})\end{array}$ & $\begin{array}{l}\text { Extraction } \\
\text { yield }(\%)\end{array}$ & $\begin{array}{l}\text { TPC yield } \\
(\mathrm{mg} / \mathrm{g})\end{array}$ \\
\hline HRE & $10.34 \pm 1.58$ & $2.34 \pm 0.93$ & $14.07 \pm 0.75$ & $10.24 \pm 1.19$ & $13.25 \pm 1.70$ & $14.12 \pm 3.22$ & $9.95 \pm 0.60$ & $4.70 \pm 0.38$ \\
\hline MAE & $10.50 \pm 0.57$ & $1.80 \pm 0.48$ & $15.54 \pm 1.22$ & $10.91 \pm 0.52$ & $20.06 \pm 1.35$ & $24.29 \pm 4.61$ & $13.09 \pm 0.77$ & $5.44 \pm 0.54$ \\
\hline
\end{tabular}

Tabla 4. Comparison of the phenolic compounds profile detected by HPLC assay in the MAE and HRE extracts

\begin{tabular}{|c|c|c|c|c|c|c|c|c|c|}
\hline \multirow[b]{3}{*}{$\begin{array}{l}\text { Phenolic } \\
\text { compound }\end{array}$} & \multirow[b]{3}{*}{$\begin{array}{l}\text { Retention } \\
\text { Time (min) }\end{array}$} & \multicolumn{8}{|c|}{ Plants extracts } \\
\hline & & \multicolumn{2}{|c|}{ J. dioica } & \multicolumn{2}{|c|}{ F. сегnиа } & \multicolumn{2}{|c|}{ E. camaldulensis } & \multicolumn{2}{|c|}{ T. diffusa } \\
\hline & & HRE & MAE & HRE & MAE & HRE & MAE & HRE & MAE \\
\hline Pyrogallol & 6.50 & - & - & - & + & - & - & - & - \\
\hline Gallic acid & 7.46 & - & - & - & - & - & - & - & - \\
\hline Resorcinol & 9.51 & - & - & - & + & - & - & - & - \\
\hline Chlorogenic acid & 11.05 & - & - & + & - & - & - & - & - \\
\hline Methyl gallate & 12.99 & - & - & - & + & - & - & - & - \\
\hline Coumaric acid & 15.09 & - & - & + & - & - & - & - & - \\
\hline Catechin & 15.65 & - & - & - & + & + & + & - & - \\
\hline 2-hydroxycinnamic acid & 17.76 & - & - & - & - & - & - & - & - \\
\hline Ellagic acid & 18.83 & - & - & - & - & - & - & - & - \\
\hline Quercetin & 20.11 & - & + & + & + & - & - & + & + \\
\hline Cinnamic acid & 21.05 & - & - & - & - & - & - & - & - \\
\hline
\end{tabular}

Presence (+) and absence (-)

\section{DISCUSSION}

Several studies have shown that the phenolics with multiple hydroxyl groups are generally the most efficient for preventing lipid oxidation (Moure et al., 2001). For $T$. diffusa extracts no significant differences between MAE and HRE procedures were observed in lipid oxidation inhibition with $60 \%$ of activity (Fig. 3b). Quality and quantity of the extracts dependent of the target compounds structures, natural sources and type of processes (Karacabey et al., 2011), this explain the fact that with MAE procedure obtained different phenolic composition in the extracts. These findings suggest that MAE procedure is an alternative method to obtain extracts with high potential antioxidants of these plants in a few minutes, compared with the conventional method. MAE has a promising future, due to the great advantages and the development of equipment for largescale commercial operation (Taamalli et al., 2012). Besides, the extracts obtained are a source of natural antioxidants which could be used in the food industry. Is important mention that naturally in antioxidants also need safety test (Moure et al., 2001). In the cases of eucalyptus leaf extract, it is included as an antioxidant natural food additive in the list of Existing Food Additives in Japan (Amakura et al., 2002).

\section{CONCLUSION}

The results obtained of solid-liquid extraction of TPC using MAE procedure were accurately described with the models used in the present study. The best temperature of extraction was $60^{\circ} \mathrm{C}$, resulting in an increase on TPC yield and reduced the time from hours to minutes. The MAE procedure is a good alternative for the extraction of natural antioxidants in the semiarid plants. E. camaldulensis extract was the higher in TPC and antioxidant activity. In contrast, $J$. dioica was the extract that showed the lower TPC and antioxidant activity. MAE procedure is a promising technique in recovery of bioactive compounds of plants in an environmentally sustainable way, but further studies about optimization in MAE procedure in the plants investigated is necessary in order to evaluate all parameter that affect the extraction efficiency. Also, it is important to mention that is necessary to determine the bioavailability the phenolic compounds of the extracts.

\section{ACKNOWLEDGEMENT}

Researchers Wong-Paz and Muñiz-Marquez are grateful to Mexican Council for Science and Technology (CONACYT) for the financial support as graduate scholarship. 


\section{REFERENCES}

Amakura, Y., Y. Umino, S. Tsuji, H. Ito and T. Hatano et al., 2002. Constituents and their antioxidative effects in eucalyptus leaf extract used as a natural food additive. Food Chem., 77: 47-56. DOI: $10.1016 / \mathrm{S} 0308-8146(01) 00321-1$

Aspé, E. and K. Fernández, 2011. The effect of different extraction techniques on extraction yield, total phenolic and anti-radical capacity of extracts from Pinus radiata Bark. Indust. Crops Products, 34: 838844. DOI: $10.1016 /$ j.indcrop.2011.02.002

Bakkali, F., S. Averbeck, D. Averbeck and M. Idaomar, 2008. Biological effects of essential oils. Food Chemical Toxicol., 46: 446-475. DOI: 10.1016/j.fct.2007.09.106

Ballard, T.S., P. Mallikarjunan, K. Zhou and S. O'Keefe, 2010. Microwave-assisted extraction of phenolic antioxidant compounds from peanut skins. Food Chem., 120: 1185-1192. DOI: 10.1016/j.foodchem.2009.11.063

Bondet, V., W. Brand-Williams and C. Berset, 1997. Kinetics and mechanisms of antioxidant activity using the DPPH• free radical method. LWT-Food Sci. Technol., pp: 609-615. DOI: 10.1006/fstl.1997.0240

Castillo, R., R. Rodríguez, J. Ventura, R. Belmares and C.N. Aguilar, 2008. Antibacterial and antioxidant activities of polyphenolic extracts from Mexican semiarid plants pre and post-fementation. Innovations in Food Science and Food Biotechnology in Developing Countries, AMECA, Querétaro, México.

Chan, C.H., R. Yusoff, G. Ngoh and F.W. Kung, 2011. Microwave-assisted extraction of active ingredients from plants-A review. J. Chromatography A, 1218: 6213-6225. DOI: 10.1016/j.chroma.2011.07.040

Sanchez-Aldana, D., C.N. Aguilar, G.V. NevarezMoorillon and J.C. Contreras Esquivel, 2013. Comparative extraction of pectic and polyphenols from mexican lime pomace and bagasse. Am. J. Agric. Biol. Sci., 8: 309-322. DOI: 10.3844/ajabssp.2013.309.322

Hao, L., W. Han, S. Huang, B. Xue and X. Deng, 2002. Microwave-assisted extraction of artemisinin from Artemisia annua. Separation Purification Technol., 28: 191-196. DOI: 10.1016/S1383-5866(02)00043-6

Ho, C.H.L., J.E. Cacace and G. Mazza, 2008. Mass transfer during pressurized low polarity water extraction of lignans from flaxseed meal. J. Food Eng., $\quad 89$ : 64-71. DOI: 10.1016/j.jfoodeng.2008.04.003
Huang, D., B. Ou and R.L. Prior, 2005. The chemistry behind antioxidant capacity assays. J. Agric. Food Chem., 53: 1841-1856. DOI: 10.1021/jf030723c

Jasso de Rodriguez, D., R. Rodriguez, F.D. Hernandez, C.N. Aguilar and A. Saenz et al., 2011. In vitro antifungal activity of extracts of Mexican Chihuahuan desert plants against postharvest fruit fungi. Industrial Crops Products, 34: 960-966. DOI: 10.1016/j.indcrop.2011.03.001

Kähkönen, M.P., A.I. Hopia and M. Heino, 2001. Berry phenolics and their antioxidant activity. J. Agric. Food Chem., 49: 4076-4082. DOI: 10.1021/jf010152t

Karacabey, E., L. Bayindirli, N. Artik and G. Mazza, 2011. Modeling solid-liquid extraction kinetics of trans-resveratrol and trans-e-viniferin from grape cane. J. Food Process Eng. DOI: 10.1111/j.17454530.2011.00660.x

Keith, L.H., L.U. Gron and J.L. Young, 2007. green analytical methodologies. Chemical Rev., 107: 2695-2708. DOI: 10.1021/cr068359e

Li, H., Z. Deng, T. Wuc, R. Liu and S. Loewen et al., 2012. Microwave-assisted extraction of phenolics with maximal antioxidant activities in tomatoes. Food Chem., 130: 928-936. DOI: 10.1016/j.foodchem.2011.08.019

Makkar, H., 1999. Quantification of tannins in tree foliage. A Laboratory Manual for the FAO/IAEA. Vienna.

Martínez, C.G., A.F. Aguilera, R. Rodríguez and C.N. Aguilar, 2011. Fungal enhancement of the antioxidant properties of grape waste. Annals Microbiol., 62: 923930. DOI: $10.1007 / \mathrm{s} 13213-011-0329-\mathrm{z}$

Martins, S., C.N. Aguilar, I. De la Garza, S.I. Mussato and J.A. Teixeira, 2010. Kinetic study of nordihydroguaiaretic acid recovery from Larrea tridentata by microwave-assisted extraction. J. Chemical Technol. Biotechnol., 85: 1142-1147. DOI: $10.1002 /$ jctb. 2412

Molyneux, P., 2004. The use of the stable free radical Diphenylpicryl-Hydrazyl (DPPH) for estimating antioxidant activity. Songklanakarin J. Sci. Technol.

Moure, A., J.M. Cruz, D. Franco, J.M. Domínguez and J. Sineiro et al., 2001. Natural antioxidants from residual sources. Food Chem., 72: 145-171. DOI: 10.1016/S0308-8146(00)00223-5

Oliveira, I., A. Sousa, I. Ferreira, A. Bento and L. Estevinho et al., 2008. Total phenols, antioxidant potential and antimicrobial activity of walnut (Juglans regia L.) green husks. Food Chemical Toxicol., 46: 2326-2331. DOI: 10.1016/j.fct.2008.03.017 
Périno, S., Z. Huma, M. Abert and F. Chemat, 2011. Solvent free microwave-assisted extraction of antioxidants from sea buckthorn (Hippophae rhamnoides) food by-products. Food Bioprocess Technol., 4: 1020-1028. DOI: 10.1007/s11947-0100438-x

Prior, R.L., X. Wu and K. Schaich, 2005. Standardized methods for the determination of antioxidant capacity and phenolics in foods and dietary supplements. J. Agric. Food Chem., 53: 4290-4302. DOI: $10.1021 /$ jf0502698

Routray, W. and V. Orsat, 2011. Microwave-assisted extraction of flavonoids: A review. Food Bioprocess Technol., DOI 10.1007/s11947-011-0573-z

Ruiz-Martínez, J., J.A. Ascasio, R. Rodríguez, D. Morales and C.N. Aguilar, 2011. Phytochemical screening of extracts from some Mexican plants used in traditional medicine. J. Med. Plants Res., 5: 2791-2797.

Starzynska, A., B. Stodolak and M. Jamróz, 2008. Antioxidant properties of extracts from fermented and cooked seeds of Polish cultivars of Lathyrus sativus. Food Chem., 109: 285-292. DOI: 10.1016/j.foodchem.2007.12.028

Taamalli, A., D. Arráez, E. Ibañez, M. Zarrouk and A. Segura et al., 2012. Optimization of microwaveassisted extraction for the characterization of olive leaf phenolic compounds by using HPLCESI- TOFMS/IT-MS2. J. Agric. Food Chem., 60: 791-798. DOI: $10.1021 / \mathrm{jf} 204233 \mathrm{u}$
Wu, T., J. Yan, R. Liu, M.F. Marcone and H.A. Aisa et al., 2012. Optimization of microwave-assisted extraction of phenolics from potato and its downstream waste using orthogonal array design. Food Chem., 133: 1292-1298. DOI: 10.1016/j.foodchem.2011.08.002

Yan, M.M., W. Liu, Y.J. Fu, Y.G. Zu and C.Y. Chen et al., 2010. Optimisation of the microwaveassisted extraction process for four main astragalosides in Radix Astragali. Food Chem., 119: 1663-1670. DOI: 10.1016/j.foodchem.2009.09.021

Yemis, O. and G. Mazza, 2012. Optimization of furfural and 5-hydroxymethylfurfural production from wheat straw by a microwave-assisted process. Bioresource Technol., 109: 215-223. DOI: $10.1016 /$ j.biortech.2012.01.031

Zuorro, A. and R. Lavecchia, 2013. Influence of extraction conditions on the recovery of phenolic antioxidants from spent coffee grounds. Am. J. $\begin{array}{llll}\text { Applied Sci., 10: } & 478-486 . \quad \text { DOI: } \\ 10.3844 / \text { ajassp.2013.478.486 } & \end{array}$ 